\title{
Postdural puncture headache: Is epidural saline patch effective - A case report
}

\author{
Ravi Prakash', Shefali Gautam1, S. Jafa ${ }^{3}$, Archana1 \\ ${ }^{1}$ Department of Anesthesiology and Critical Care, King George's Medical University, Lucknow, Uttar Pradesh, India
}

\section{A B S T R A C T}

Postdural puncture headache (PDPH) is a major complication of lumber puncture or accidental dural puncture especially in patients with raised intrabdominal pressure like pregnancy, abdominal tumors etc. Many interventions have been tried to prevent and treat PDPH. None of them is $100 \%$ effective and variable success rates have been reported. We present a case of successful use of epidural saline patch to treat PDPH caused by accidental dural puncture in a 45 yrs female with large ovarian tumor.

Key words: PDPH, epidural saline patch, ovarian tumor, blood patch
Access this article online

\section{Website:}

http://nepjol.info/index.php/AJMS

\section{INTRODUCTION}

Postdural puncture headache (PDPH) has been a major complication after accidental dural puncture during epidural catheter placement. The incidence of PDPH has been shown to be around $50-80 \%$ after accidental dural puncture by Touhy needle. ${ }^{1}$ Many methods have been tried to prevent and treat PDPH with variable success rate. Many factors have been proposed to affect the development of PDPH. We present a case of $45 \mathrm{yrs}$ old female suffering from ovarian malignancy posted for staging laparotomy. She had an accidental dural puncture by 18 gaze Touhy needle and suffered PDPD, which was successfully treated with epidural saline patch.

\section{CASE HISTORY}

A 45 yrs old $50 \mathrm{~kg}$ female was admitted to general surgery department with complaints of progressive abdominal distension since 1 yrs. She also had complained of increased frequency of urination since 2 months. She also complained of dyspnoea on exertion due to gross abdominal distention. Her vitals were: HR-80/min, B.P.-108/60 $\mathrm{mmHg}$ and RR-16/min. She was examined and investigated and diagnosed to be a case of ovarian tumor of size $28.2 \times 22.0 \mathrm{~cm}$. Her CT abdomen showed large fluid filled mass causing pressure effects over pelvic organs. No free fluid was seen in peritoneal and pleural cavity. Her hematological investigations, renal and hepatic functions test were normal.

Staging laparotomy was planned under combined spinalepidural anesthesia (CSE). In the OT, standard monitors were applied and intravenous access was secured. After preloading with $500 \mathrm{ml}$ of ringer lactate (RL), an 18 gz Touhy needle was used to place a $20 \mathrm{gz}$ epidural catheter in L3-L4 intervertebral space but accidently dura was punctured during needle insertion. We removed the needle and waited for $10 \mathrm{~min}$ and again Touhy needle was reinserted in L1-L2 intervertebral space and catheter was placed $3 \mathrm{~cm}$ in epidural space in cehaloid direction. Spinal anesthesia was given in L2-L3 intervertebral space using 25 gz quincke needle with $3 \mathrm{ml} \mathrm{0.5 \%}$ bupivacaine and $25 \mathrm{mcg}$ fentanyl. Anaesthesia of sensory level upto T6 was achieved and the surgery was started. Patient was sedated with $2 \mathrm{mg}$ of midazolam. Ovarian tumor was removed after $1 \mathrm{hr}$ of initiation of surgery (Figures 1 and 2). Just after removal of tumor, patient had an episode of hypotension (B.P. $80 / 50 \mathrm{mmHg}$ ) which was treated successfully with fluid bolus of $500 \mathrm{ml} \mathrm{RL}$ and inj mephentermine $6 \mathrm{mg}$ bolus and B.P. was maintained at 110-115/70-80 mmHg. After $15 \mathrm{~min}$, patient started complaining of severe headache in frontal region associated with nausea and diplopia. Inj. Ondensetron $4 \mathrm{mg}$ IV was given to treat nausea. Inj. Diclofenac 75 IV and fluid bolus of $300 \mathrm{ml} \mathrm{RL}$ was given but she did not have pain relief. Suspecting it to be PDPH, $30 \mathrm{ml}$ normal saline 
was given through epidural catheter which was placed before starting surgery. Patient had complete pain relief in another $15 \mathrm{~min}$. Surgery was completed in $1.5 \mathrm{hrs}$. Patient was shifted to postoperative ward. She recovered fully form subarachnoid block after 3 hrs. She didn't complain of headache again. Inj. Tramadol $50 \mathrm{mg}$ TDS was given for postoperative analgesia. Epidural catheter was removed 48 hrs after surgery. Her neurological examination was within normal limits and her postoperative period was uneventful. A CT scan of head was done to rule out other causes of headache. After one week, she was transferred to oncology department for further treatment of ovarian tumor.

\section{DISCUSSION}

Post-dural puncture headache (PDPH) was first described by August Bier in 1898 when he performed spinal anaesthsia on himself. PDPH is classically described as a frontoccipital headache following therapeutic or diagnostic interventions causing dural breach. The incidence of PDPH is estimated to be between $30-50 \%$ following diagnostic or therapeutic lumbar puncture, 0-5\% following spinal anaesthesia and

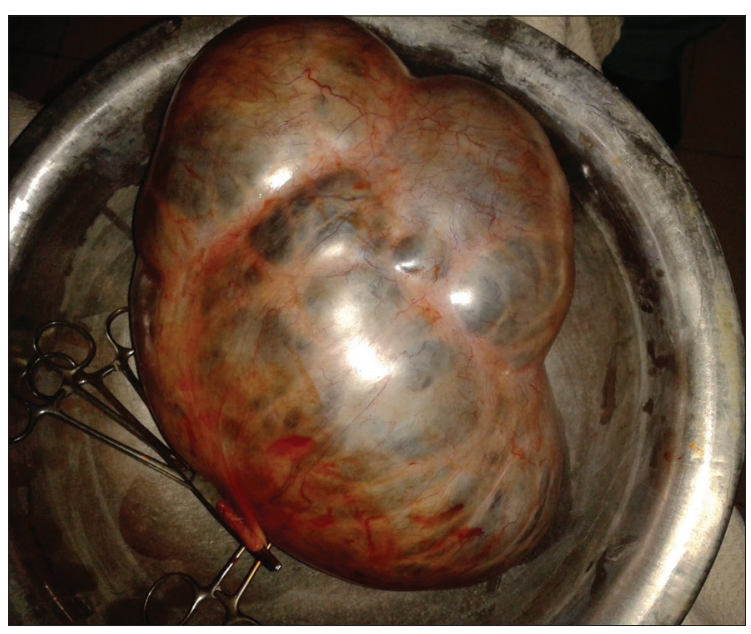

Figure 1: Ovarian tumor after resection

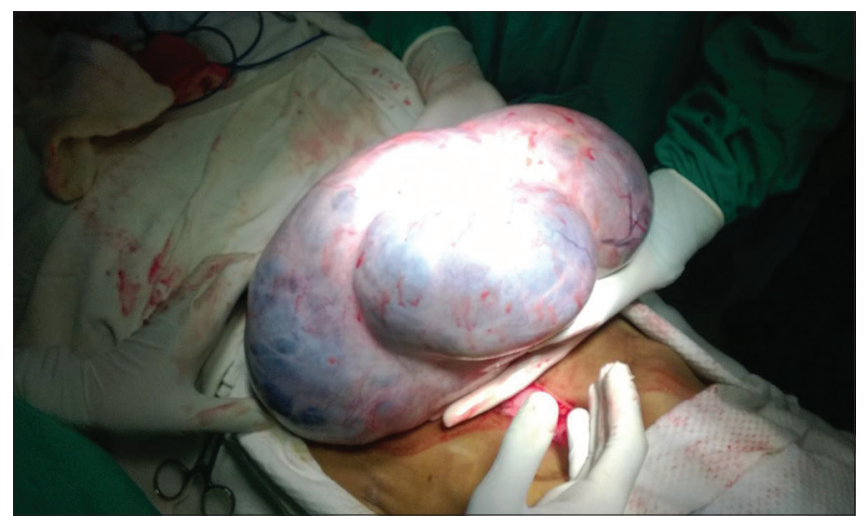

Figure 2: Ovarian tumor during surgery up to $81 \%$ following accidental dural puncture during epidural insertion in the pregnant woman. Although PDPH resolves spontaneously, it causes unacceptable discomfort to the patient. PDPH may be associated with serious complications such as subdural hematoma, seizures and saggital sinus thrombosis. ${ }^{1}$

Other causes of headache that must be ruled out before diagnosing PDPH includes: hypoglycemia, meningitis, encephalitis, dehydration, caffeine withdrawal, vascular migraine, cerebral vein thrombosis, cerebral infarction, subdural hematoma, subarachnoid/subdural hematoma, pre-eclampsia, tension headache, benign intracranial hypertension, pneumocephalus, lactation headache and space occupying lesion. ${ }^{1,7}$

Its prophylaxis and treatment has been studied and discussed for more than 100 years, but the evidence is still limited. Due to relatively low prevalence of PDPH, prospective RCTs are often missing, and the frequently self-limiting character of PDPH impedes an adequate interpretation of results from studies without a control group. Taking side effects and complications into account, a prophylactic treatment of PDPH cannot be recommended. In case of PDPH, bed rest, adequate fluids and non-opioid analgesics are the first choice treatment. The epidural blood patch remains the mainstay of severe PDPH therapy. Noninvasive therapies like theophylline, caffine, sumatriptan and ACTH can be an alternative. However, an evidence-based recommendation is lacking. ${ }^{2,8,9}$ Other methods used for treatment of PDPH include intrathecal catheter, fibrin glue, epidural morphine, epidural dextran and epidural saline patch. ${ }^{1}$

Epidural saline patch has been used with variable success in prevention and treatment of PDPH. It may be accompanied with continuous infusion of saline in epidural space for $24 \mathrm{hrs}$. Usually $20-30 \mathrm{ml}$ of saline is used as bolus followed by infusion at up to 1-2 litres/day. Various case reports have shown its efficacy in treatment of PDPH and some studies have shown inconclusive results. ${ }^{3,10}$

PDPH usually develops within 24-48 hrs after dural tear but not immediately. ${ }^{4-6}$ In our case, the cause of early development of PDPH may be due to sudden decrease in intrabdominal and CSF pressure after removal of large ovarian tumour. We infused $30 \mathrm{ml}$ saline which relieved headache. We didn't started continuous infusion as patient not complained of pain thereafter. We kept the epidural catheter in place for 48 hrs, so it can be used for saline infusion.

We therefore recommend the use of saline epidural patch before using epidural blood patch as it is associated with less 
complication than the later and it can be used where epidural blood patch is contraindicated as in presence of sepsis.

\section{REFERENCES}

1. Turnbull DK and Shepherd DB Post-dural puncture headache: pathogenesis, prevention and treatment. Br. J. Anaesth. 2003; 91 (5):718-729.

2. Kleine-Brüggeney $M$, Kranke $P$ and Stamer UM. Prophylaxis and therapy of postdural puncture headache--a critical evaluation of treatment options. Anasthesiol Intensivmed Notfallmed Schmerzther. 2011 Jul; 46(7-8):516-24. Doi:10.1055/s-0031-1284471.

3. Liu SK, Chen KB, Wu RS, Lin BC, Chang CS, Liu YC et al. Management of postdural puncture headache by epidural saline delivered with a patient-controlled pump--a case report. Acta Anaesthesiol Taiwan. 2006 Dec; 44(4): 227-30.

4. Silberstein SD and Marcelis J. Headache associated with changes in intracranial pressure. Headache 1992; 32 : 84-86.
5. Headache Classification Committee of the International Headache Society. The International Classification of Headache Disorders: $2^{\text {nd }}$ edition. Cephalalgia 2004; 24 (suppl 1): 9-160.

6. Evans RW, Armon C, Frohman EM and Goodin DS. Assessment: Prevention of post-lumbar puncture headaches: Report of the therapeutics and technology assessment subcommittee of the American Academy of Neurology. Neurology 2000; 55: 909-911.

7. Landman UN, Jerome RM and Glass PS. Subdural hematoma after atraumatic spinal. J. Clin. Anesthesia 2005; 17: 379-81.

8. Apfel CC, Saxena A, Cakmakkaya OS, Gaiser R, George E and Radke O. Prevention of Postdural Puncture Headache after Accidental Dural Puncture: A Quantitative Systematic Review. Br J Anaesth. 2010; 105(3):255-263.

9. Boonmak $\mathrm{P}$ and Boonmak S. Epidural blood patching for preventing and treating post-dural puncture headache. Cochrane Database Syst Rev. 2010 Jan; 20(1):CD001791.

10. Kara I, Ciftci I, Apiliogullari S, Arun O, Duman A and Celik JB. Management of postdural puncture headache with epidural saline patch in a 10-year-old child after inguinal hernia repair: a case report. J Pediatr Surg. 2012 Oct;47(10):e55-e57.

\author{
Authors Contribution: \\ RP, A, SJ - conducted case, drafted manuscript, review of literature, revision of manuscript; SG - revision of manuscript.
}

Source of Support: Nil, Conflict of Interest: None declared. 